\title{
Erratum: Expression of growth arrest-specific protein 6 and AxI molecules in the left internal mammary artery of patients undergoing coronary artery bypass grafting
}

Lee CH, Shieh YS, Tsai CS, et al. Expression of growth arrest-specific protein 6 and Axl molecules in the left internal mammary artery of patients undergoing coronary artery bypass grafting. J Clin Pathol 2014;67:506-11. doi:10.1136/jclinpath-2013-202000.

1. Authors acknowledge that Figure 2 is a duplication of Figure 1E.

2. Authors mention the use of age-adjusted Spearman partial correlation analysis in the 'Results' section of the paper (page 509, line 4-5), but the $\mathrm{r}$ and $\mathrm{P}$ value in figure 3 are not age-adjusted. The revised figures 3 with the correct $\mathrm{r}$ and $\mathrm{P}$ value after adjusting of age are below:
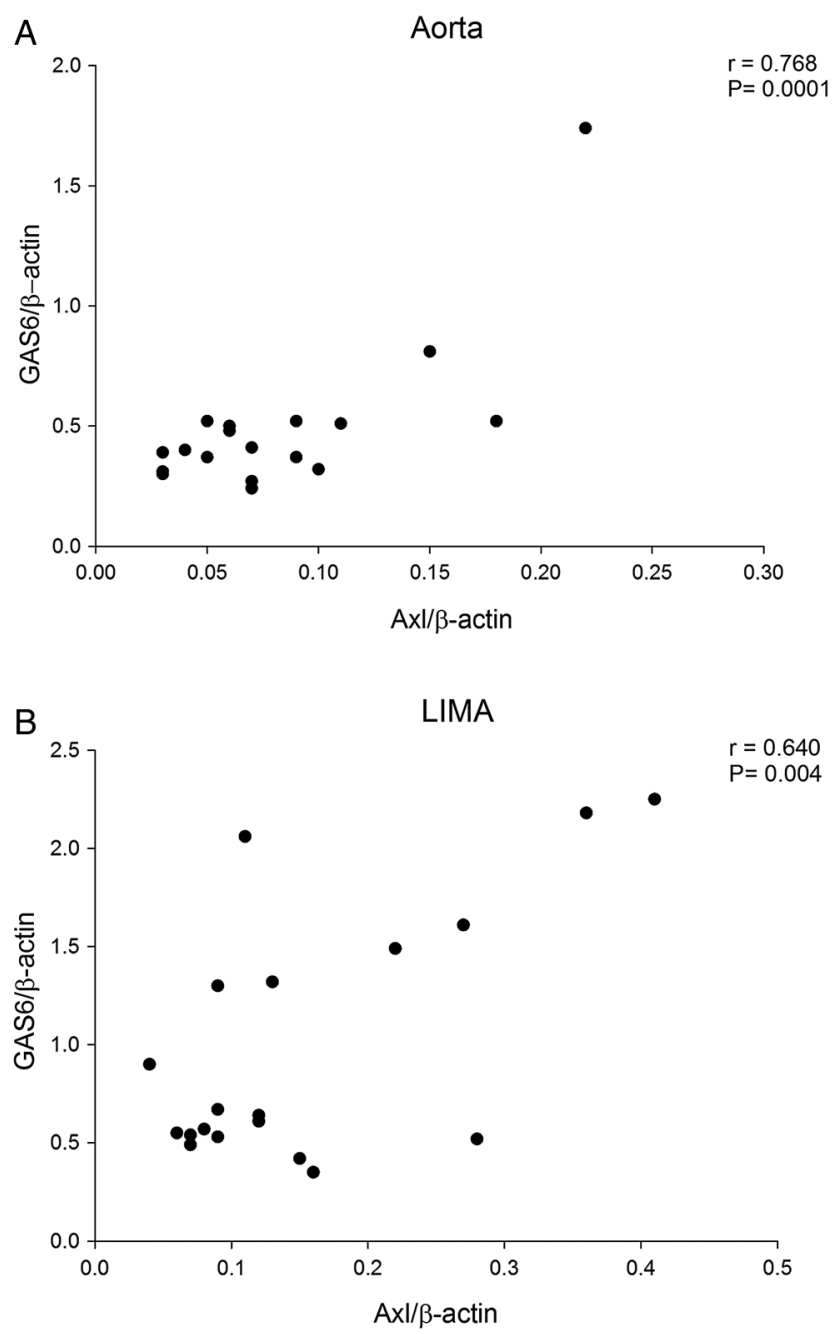